\title{
A INTEGRAÇÃO DO CONHECIMENTO GEOGRÁFICO: PERSPECTIVAS CRÍTICAS DA ABORDAGEM GEOSSISTÊMICA
}

\author{
Caio Faria da Cunha Barbosa Adorno ${ }^{1}$ \\ Clibson Alves dos Santos ${ }^{2}$ \\ André Mateus Barreiros ${ }^{3}$
}

RESUMO: A abordagem sistêmica modificou a maneira de se trabalhar as questões relativas à sociedade e a natureza. Na Geografia, foi o paradigma geossistêmico que passou a vigorar sobre o modo de se analisar o espaço com preocupações nesta dualidade. Sochava (1968) e Bertrand (1972) foram os precursores do termo e definiram o geossistema como uma alternativa de caráter heterogêneo e dinâmico para a análise da paisagem de maneira sistêmica e holística. A literatura geográfica brasileira, principalmente com estudos ambientais, tem trabalhado o espaço pela perspectiva geossistêmica. O presente artigo buscou elaborar uma revisão bibliográfica da consagração do termo "geossistema" seguido de uma crítica de como as abordagens têm sido realizadas com a diminuição da complexidade do binômio sociedade-natureza. Busca contribuir para o cenário da ciência geográfica com perspectivas críticas da abordagem holista em prol do planejamento espacial.

PALAVRAS-CHAVE: Geomorfologia; geossistemas; planejamento urbano; holismo; geografia.

\section{THE GEOGRAPHIC KNOWLEDGE INTEGRATION: CRITICAL REVIEWS ON GEOSSYSTEMIC APPROACHES}

ABSTRACT: The systemic approach changed the way of working on issues related to society and nature. At Geography, it was the geosystemic paradigm that came into effect about how to analyze the space with concerns on this duality. Sochava (1963) and Bertrand (1968) were the precursors of the term and had defined a geosystem as heterogenic and

\footnotetext{
${ }^{1}$ Aluno do Programa de Pós Graduação em Geografia da Universidade Federal de Alfenas (PPGeo - UNIFAL). Grupo de Pesquisa em Análise Espacial e Dinâmica Ambiental (GAEDA). E-mail: caioadorno31@gmail.com

${ }^{2}$ Professor associado da Universidade Federal de Alfenas (UNIFAL), associado ao Programa de PósGraduação em Geografia da Universidade Federal de Alfenas. Diretor do grupo de Pesquisa em análise espacial e dinâmica ambiental (GAEDA). E-mail: clibsonsantos@gmail.com

${ }^{3}$ Colaborador no Programa de Geografia Física da USP; Doutor e Pós-Doutorado em Geografia pela USP. E-mail: andrembarreiros@gmail.com
} 
dynamic alternative to the landscape analysis in systemic and holist ways. The Brazilian geographic literature, mainly environment papers, usually works the space according to the geosystemic perspective. The present paper sought to elaborate a bibliographic review about the consecration of the "geosystem" term, followed by a critic about how these approaches have been carried out with the reduction of the complexity of the society-nature binomial. It seeks to contribute to the geographic science scenario with critics perspectives about the holistic approaches for the sake of spatial planning.

KEYWORDS: Geomorphology; geosystem; urban planning; holism; geography.

\section{LA INTEGRACIÓN DEL CONOCIMIENTO GEOGRÁFICO: PERSPECTIVAS CRÍTICAS DEL ENFOQUE GEOSISTÉMICO}

RESUMEN: El enfoque sistémico cambió la forma de trabajar en temas relacionados con la sociedad y la naturaleza. En geografía, fue el paradigma geosistémico el que entró en vigencia sobre cómo analizar el espacio con inquietudes sobre esta dualidad. Sochava (1963) y Bertrand (1968) fueron los precursores del término y habían definido un geosistema como alternativa heterogénea y dinámica al análisis del paisaje en formas sistémicas y holistas. La literatura geográfica brasileña, principalmente artículos ambientales, suele trabajar el espacio de acuerdo con la perspectiva geosistémica. El presente trabajo buscó elaborar una revisión bibliográfica sobre la consagración del término "geosistema", seguida de una crítica sobre cómo se han llevado a cabo estos enfoques con la reducción de la complejidad del binomio sociedad-naturaleza. Busca contribuir al escenario de la ciencia geográfica con perspectivas críticas sobre los enfoques holísticos en aras de la planificación espacial.

PALABRAS CLAVE: Geomorfología; geosistema; urbanismo; holismo; geografía.

\section{INTRODUÇÃO}

A complexa dicotomia entre a sociedade e a natureza tem proporcionado questões desafiadoras que tangem ao exercício da organização do espaço geográfico (NUNES, 2012). É recorrente um cenário de contradições ambientais em sistemas naturais, principalmente naqueles em que a ação antrópica tem se estabelecido de maneira abusiva (GUERRA; MARÇAL, 2006).

Compreender áreas naturais como o reflexo da relação entre os elementos da natureza no espaço geográfico e, entre eles, a sociedade humana, é uma ideia 
que tem ganhado força na literatura geográfica brasileira (CAVALCANTI; CORRÊA, 2016). Somado a essa concepção, a premissa da superfície terrestre como essencial à evolução da sociedade e como suporte à interação humana com a natureza, se destaca o conceito de paisagem.

No decorrer da história do pensamento geográfico foi constituída a busca pela compreensão da paisagem em sua totalidade, através do paradigma holístico (DUTRA GOMES; VITTE, 2018). Alexander Von Humboldt é um dos precursores deste paradigma, e em suas observações objetivou a análise da paisagem a partir das conexões entre seus componentes, em busca da compreensão integrada da totalidade dos processos e das formas (WULF, 2016).

A interação das esferas sociais e ambientais transforma a paisagem (NUNES, 2014), logo, torna-se necessário a elaboração de teorias que possam nortear a compreensão dessa relação complexa. Neste contexto, surge na Geografia a busca de uma abordagem capaz de conectar os fatores físicos aos humanos (CHRISTOFOLETTI, 1999). Nesta procura por uma abordagem holística da natureza, o soviético Sochava (1968) e o francês Bertrand (1972), apoiados na Teoria Geral dos Sistemas de Ludwig Von Bertalanffy (1950), discutem a Teoria dos Geossistemas (RODRIGUES, 2001).

O conceito de geossistemas constrói uma proposta integradora de caráter heterogêneo e dinâmico para a paisagem, já que aborda de maneira sistêmica a paisagem como um todo (BERTRAND, 1972; CHRISTOFOLETTI, 1999; MONTEIRO, 2001). Adotando a paisagem como um sistema aberto, de relação constante com os elementos que a compõem, a análise geossistêmica compreende a totalidade como resultado das interações e inter-relações dos componentes (RODRIGUEZ, 2015).

A leitura da complexidade ambiental, pelo paradigma geossistêmico, traz à tona a necessidade de realçar a conexão entre os níveis de organização espacial com os mecanismos endógenos e exógenos da Terra (DUTRA GOMES e VITTE, 
2018). Em busca de melhorias na gestão e planejamento do espaço, a Teoria dos Geossistemas precisa se adaptar às mudanças e permanências do espaço-tempo da humanidade, que compõe uma parte do quadro natural (DUTRA GOMES; VITTE, 2017).

Neste contexto, a análise da paisagem pelo viés geossistêmico deve assumir a complexa realidade de cada recorte definido. Logo, deve-se considerar que as abordagens generalistas desconsideram a heterogeneidade do paradigma geossistêmico. Ora, se a modelização deste paradigma se fixa na dinâmica dos fatores antropogênicos e naturais correspondentes, a integração entre eles deve partir das singularidades de cada escala e recorte definidos para a análise.

O objetivo principal deste texto é contribuir na discussão do papel do profissional geógrafo na transformação do espaço geográfico, principalmente através das aplicações que o paradigma dos geossistemas tem a oferecer para esse propósito. O trabalho se baseia na análise bibliográfica, produzida nos últimos vinte anos, acerca da Teoria dos Geossistemas. Busca elaborar uma crítica sobre a generalização que tem sido feita pelos geógrafos, principalmente nos estudos de cunho ambiental, onde a relação da sociedade com a natureza tem sua complexidade reduzida.

Neste contexto, justifica-se a elaboração desta crítica para uma contribuição na área da Geografia. A busca por um caminho integrador dos conhecimentos da episteme geográfica, que envolve o físico e o humano, é necessária para a concretização dos objetivos desta ciência, como a organização espacial.

\section{METODOLOGIA}

O presente texto buscou trabalhos que se preocuparam com a questão geossistêmica na Geografia. Foram levantados artigos que assumiram a Teoria dos Geossistemas como proposta de análise do espaço (Tabela 1). Além dos 
artigos, os autores também realizaram a leitura da obra de Carlos Augusto Figueiredo de Monteiro, intitulada "Geossistemas: a história de uma procura", de 2001. Em seu trabalho, Monteiro destaca a falta de articulação da unidade geográfica e a dificuldade de articulação entre a complexidade emergente da dualidade epistêmica sociedade e natureza.

Tabela 1: Artigos consultados nos periódicos de geografia.

\begin{tabular}{|c|c|c|c|}
\hline Revista & Título do artigo & Ano & Autor (ES) \\
\hline $\begin{array}{l}\text { Sociedade } \\
\text { Natureza }\end{array}$ & $\begin{array}{l}\text { Novas Considerações sobre } \\
\text { geossistemas e } \\
\text { organizações espaciais em } \\
\text { geografia }\end{array}$ & 2018 & $\begin{array}{lr}\text { DIAS, } & \text { Renê Lepiani; } \\
\text { FILHO, } & \text { Archimedes } \\
\text { Perez. } & \end{array}$ \\
\hline $\begin{array}{l}\text { Sociedade } \\
\text { Natureza }\end{array}$ & $\begin{array}{l}\text { Análise das paisagens do } \\
\text { litoral sul do estado de São } \\
\text { Paulo }\end{array}$ & 2012 & $\begin{array}{l}\text { DIAZ, Renê Lepiani; } \\
\text { OLIVEIRA, Regina Celia. }\end{array}$ \\
\hline $\begin{array}{l}\text { Sociedade } \\
\text { Natureza }\end{array}$ & $\begin{array}{l}\text { A importância dos } \\
\text { geossistemas na pesquisa } \\
\text { geográfica: Uma análise a } \\
\text { partir da correlação com o } \\
\text { ecossistema }\end{array}$ & 2014 & $\begin{array}{l}\text { NEVES, Carlos Eduardo; } \\
\text { MACHADO, } \quad \text { Gilnei; } \\
\text { HIRATA, Carlos Alberto; } \\
\text { STIPP, Nilza Aparecida } \\
\text { Freres. }\end{array}$ \\
\hline $\begin{array}{l}\text { OKARA: } \\
\text { Geografia } \\
\text { debate }\end{array}$ & $\begin{array}{l}\text { Da teoria dos geossistemas } \\
\text { à geografia física crítica: o } \\
\text { que há de novo nas buscas } \\
\text { por abordagens } \\
\text { integradoras na ciência } \\
\text { geográfica? }\end{array}$ & 2020 & $\begin{array}{l}\text { SOUZA, Lucas Barbosa; } \\
\text { LIMA, Péricles Souza; } \\
\text { SANTOS, } \\
\text { Rodrigues. }\end{array}$ \\
\hline $\begin{array}{l}\text { Revista do } \\
\text { Departamento } \\
\text { de Geografia } \\
\text { (USP) }\end{array}$ & $\begin{array}{l}\text { O Geossistema } \\
\text { Complexidade: } \\
\text { releitura das } \\
\text { Geográficas }\end{array}$ & 2018 & $\begin{array}{l}\text { DUTRA GOMES, } \\
\text { Rodrigo; VITTE, Antonio } \\
\text { Carlos. }\end{array}$ \\
\hline
\end{tabular}




\begin{tabular}{|c|c|c|c|}
\hline GEOSUL & $\begin{array}{l}\text { A Geografia Física e o objeto } \\
\text { complexo: } \quad \text { algumas } \\
\text { flexibilizações do processual }\end{array}$ & 2009 & $\begin{array}{l}\text { DUTRA GOMES, } \\
\text { Rodrigo; VITTE, Antonio } \\
\text { Carlos. }\end{array}$ \\
\hline GEOSUL & $\begin{array}{l}\text { Problemas } \\
\text { hierarquização espacial e } \\
\text { funcional na ecologia da } \\
\text { paisagem: uma avaliação a } \\
\text { partir da abordagem } \\
\text { geossistêmica }\end{array}$ & 2013 & $\begin{array}{l}\text { CAVALCANTI, Lucas } \\
\text { Costa de Souza; } \\
\text { CORRÊA, Antonio Carlos } \\
\text { de Barros }\end{array}$ \\
\hline $\begin{array}{l}\text { Ra'e Ga: Espaço } \\
\text { Geográfico em } \\
\text { Análise }\end{array}$ & $\begin{array}{l}\text { Geossistema } \\
\text { Complexidade: sobre } \\
\text { hierarquias e diálogo entre } \\
\text { os conhecimentos }\end{array}$ & 2017 & $\begin{array}{l}\text { DUTRA GOMES, } \\
\text { Rodrigo; VITTE, Antonio } \\
\text { Carlos. }\end{array}$ \\
\hline GEOgraphia & 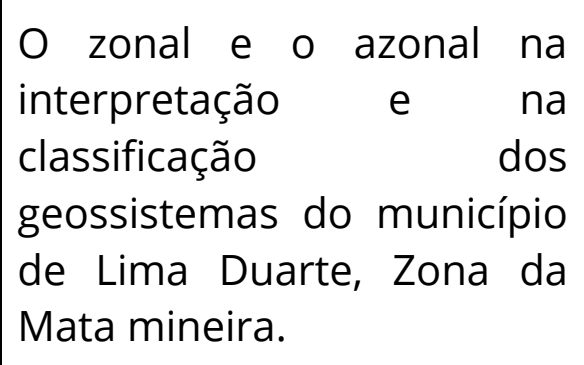 & 2019 & NETO, Roberto Marques \\
\hline GEOgraphia & $\begin{array}{l}\text { Geossistemas e } \text { Gestão } \\
\text { Ambiental na bacia } \\
\text { hidrográfica do rio São João } \\
\text { - RJ }\end{array}$ & 2004 & $\begin{array}{lr}\text { CUNHA, } & \text { Sandra } \\
\text { Baptista; } & \text { FREITAS, } \\
\text { Marcos Welausen Dias. }\end{array}$ \\
\hline $\begin{array}{lr}\text { Mercator } & - \\
\text { Revista de } & \\
\text { Geografia da UFC }\end{array}$ & Geossistemas & 2008 & $\begin{array}{l}\text { TROPPMAIR, Helmut; } \\
\text { GALINA, Marcia Helena. }\end{array}$ \\
\hline $\begin{array}{lr}\text { Mercator } & - \\
\text { Revista de } & \\
\text { Geografia da UFC }\end{array}$ & $\begin{array}{l}\text { Dinâmica Ambiental como } \\
\text { critério para o zoneamento } \\
\text { do litoral leste de Fortaleza - } \\
\text { CE }\end{array}$ & 2008 & $\begin{array}{lr}\text { CARVALHO, } & \text { Rodrigo } \\
\text { Guimarães; } & \text { MEIRELES, } \\
\text { Antonio } & \text { Jeovah } \\
\text { Andrade. } & \end{array}$ \\
\hline
\end{tabular}




\begin{tabular}{l|l|l|l}
\hline $\begin{array}{l}\text { Revista Brasileira } \\
\text { de Geografia - }\end{array}$ & $\begin{array}{l}\text { Geossistemas e Geografia } \\
\text { no Brasil }\end{array}$ & 2016 & $\begin{array}{l}\text { CAVALCANTI, Lucas } \\
\text { Costa de Souza; e } \\
\text { IBGE (Instituto } \\
\text { CORREA, Antônio Carlos } \\
\text { de Barros. } \\
\text { Geografia }\end{array}$
\end{tabular}

Desta maneira, o presente trabalho buscou analisar o caminho geossistêmico utilizado pelos trabalhos dos últimos vinte anos nas revistas acadêmicas de produção geográfica. A seleção dos artigos foi feita com base nos temas, objetivos, motivações e resultados obtidos nos trabalhos. Foram selecionadas revistas consagradas na área da Geografia, como Sociedade e Natureza; Mercator; Okara: Geografia em debate; GEOgraphia; Geosul; Raega: O espaço geográfico em análise; e Revista do Departamento de Geografia da USP (Universidade de São Paulo)

O estudo da paisagem na Geografia apresenta um sério problema de método que interfere no exercício desta ciência (BERTRAND, 1972). Quando a organização do espaço está em voga, é preciso ressaltar a falta de articulação da unidade "Geografia", que remete aos séculos XVIII e XIX (MOREIRA, 2008). Enquanto a unidade se concretizava como ciência, com rigor epistemológico, surgiam diferentes correntes do pensamento geográfico, de um lado a Geografia Física, sobre bases empíricas e naturalistas, e do outro uma Geografia Humana de cunho sociológico e histórico (MORAES, 2003).

A necessidade de compreender o espaço como uma entidade natural, formada pelas relações entre os componentes da natureza, e nestes se inclui o homem, trouxe nova dinâmica à geografia (CUNHA e FREITAS, 2004). A esfera geográfica destacava que a dinâmica dos sistemas dependia da inter-relação de 
seus componentes (CHRISTOFOLETTI, 1999). A exclusão do homem como componente da natureza é reflexo da dualidade que perturba a geografia (SOUZA et al., 2020).

A partir desta visão, o sistema considerado é resultado das interações entre suas unidades, e não da soma delas (AMORIM FILHO, 1998). Assim, ficou evidente que uma variação entre um dos componentes pode refletir no sistema como um todo (CHRISTOFOLETTI, 1999).

Uma análise subsidiada pelo axioma holístico vai considerar o todo como resultante da inter-relação de seus elementos, organizados e hierarquizados (TROPPMAIR; GALINA, 2006). Foi esta visão holística que norteou a Teoria Geral dos Sistemas, que buscou excluir a análise fragmentada por uma análise que fosse capaz de englobar todo o sistema (MONTEIRO, 2001). A teoria dos sistemas constitui um campo teórico inovador para as ciências naturais, e passou a considerar uma visão integradora de mundo (CHRISTOFOLETTI, 1999).

Com toda essa revolução do pensamento científico, com a substituição do paradigma reducionista pelo holístico, não demorou aos geógrafos perceberem que não era mais viável analisar a paisagem com enfoque isolado (MONTEIRO, 2001). Foi, então, iniciada uma nova fase do pensamento geográfico, mais especificamente, dos geógrafos ambientais que se preocupavam com a organização socioambiental e econômica (SOUZA, 2010).

A aplicação da TGS na geografia veio com a proposta de lidar com a dicotomia presente na unidade epistemológica (MONTEIRO, 2001). Foi a geografia soviética, com Sochava (1968), que primeiramente propôs uma análise geográfica apoiada na visão geossistêmica. Esta nova proposta metodológica substitui os estudos de caráter biológico-ecossistêmico por um de caráter integrador dos condicionantes físicos com os agravantes antrópicos de determinado recorte espacial (TROPPMAIR, 2007).

Sochava quis demonstrar que os recortes geossistêmicos refletem a 
interação dos elementos que compõem o sistema natural-antrópico (DUTRA GOMES; VITTE, 2009). Desta maneira, a ótica geossistêmica possibilita a compreensão da dinâmica complexa que resulta dessa interação de atributos socionaturais (ROSS, 2006).

Percebeu-se que a variável antrópica precisa ser compreendida como típica manifestação dos sistemas naturais, ou seja, como parte da própria natureza (RODRIGUES, 2001). Reconhecer a dinâmica sociocultural e econômica como características naturais de um sistema, é reconhecer a sua capacidade de alteração da paisagem (DUTRA GOMES; VITTE, 2009).

Ao mesmo tempo em que a geografia soviética de Sochava surgia com este novo paradigma, a geografia francesa também fez sua contribuição (RODRIGUEZ; SILVA, 2002). George Bertrand (1972) desenvolveu um complexo dinâmico que integra o potencial ecológico, a exploração biológica e a ação antrópica (RODRIGUEZ; SILVA, 2002), ou seja, ele destacou a influência humana junto dos fatores físicos no geossistema.

A influência e a relevância da sociedade como condicionantes da paisagem exaltam a importância de considerar o geossistema como uma possibilidade de análise do espaço (MONTEIRO, 2001). Neste sentido Bertrand e Bertrand (2007), baseado em Tricart (1977), define unidades de paisagem, as zonas superiores (Zona, Domínio e Região) e inferiores (Geossistema, Geofácie e Geócoro), e a partir delas a análise geossistêmica delimita seus recortes (NEVES et al., 2014).

A literatura nos mostra que as concepções atribuídas ao vocábulo geossistema são fundamentalmente divergentes em Bertrand e Sochava (CAVALCANTI; CORRÊA, 2016). Em um primeiro momento, Bertrand em 1972 associa os geossistemas a escalas definidas do espaço e do tempo na paisagem, enquadrando-o na $4^{\mathrm{a}}$ e $5^{\mathrm{a}}$ ordem de grandeza de Cailleux e Tricart. Essa concepção é alterada anos mais tarde, quando o próprio autor, em parceria com Beroutchachvili, discorre que os geossistemas com ordens de grandeza definida 
não consumariam uma análise precisa da paisagem, e passa a considerar o termo de acordo com a definição de Sochava (CAVALCANTI; CORRÊA, 2016).

Nesse contexto, Bertrand compreende o geossistema como um sistema natural influenciado pela dinâmica social. Essa ideia geossistêmica é utilizada como subsídio para o seu modelo Geossistema-Território-Paisagem (BERTRAND; BERTRAND, 2007). Nesse momento, o geossistema compreende a dimensão antrópica de um conceito naturalista, destacando os componentes bióticos, abióticos e culturais do sistema em um conceito temporal e histórico (OLIVEIRA, 2019). Não obstante, o território representa a dimensão econômica de um conceito social, e a paisagem elenca o discurso da representação, sensibilidade e da subjetividade (OLIVEIRA, 2019).

Tendo em vista a discussão da escola francesa, com Bertrand, acerca dos geossistemas, é preciso ressaltar que foi a escola soviética quem primeiro destacou esse método de análise da paisagem para a geografia física (BARREIROS, 2017). Sochava propõe, primeiramente, em 1963 que os geossistemas substituíssem o objeto paisagem na geografia, já que traria mais sentido e focaria essencialmente na manifestação dos elementos naturais na superfície terrestre (SEMENOV; SNYTKO, 2015).

Sochava, então, atribui ao geossistemas o sentido de unidade natural com diversas escalas (do geossistema planetário ao elementar). Divergindo de Bertrand, que atribui escala bem definida ao termo (dezenas a centenas de quilômetros quadrados), Sochava discorre a possibilidade de diversas dimensões espaciais ao conceito, como toda a superfície do planeta (chamado pelo autor de envelope geográfico) até as fácies físico-geográficas (BARREIROS, 2017).

O ideal para uma análise geográfica vem da necessidade de entender a relação de uma estrutura natural com base no modo e do sistema de produção dominante, portanto, o geossistema deriva não só desta estrutura ambiental, mas também é produto antrópico (SOUZA et al., 2020). Portanto, a análise precisa estar 
atenta à escala de abrangência da lente geográfica.

O presente trabalho considera que a teoria dos geossistemas fornece subsídio ao aporte teórico-metodológico para uma análise integradora do espaço. Considera que a avaliação dos estados dinâmicos da paisagem será mais vantajosa a partir da compartimentação das Unidades de Paisagem, como bem realizou Crepani (2001), com bases geomorfológicas, para a criação de zoneamentos geoambientais.

\section{A GEOGRAFIA BRASILEIRA NA APLICAÇÃO DA TERORIA GEOSISTÊMICA}

O ramo geossistêmico na geografia brasileira emerge, inicialmente, como uma ramificação das ideias da escola francesa de geografia (BARREIROS, 2017). O estudo de áreas naturais na escola brasileira é, comumente, atribuído a teoria sistêmica, e os geógrafos nacionais, como Aziz Ab'Saber e Carlos Augusto Figueiredo de Monteiro, ao se debruçarem sobre o tema concluíram que a compreensão integrada e holista da paisagem é essencial para resolver o problema epistêmico da dualidade sociedade e natureza (OLIVEIRA, 2019).

Os geossistemas representam, principalmente para a geografia física, uma revolução no campo teórico-metodológico. A geografia universitária é muito fragmentada e intensifica a dicotomia da unidade enquanto ciência (MONTEIRO, 2001). Cada esfera do espaço é analisada por meio de diferentes combinações em busca de padrões explicativos, e as tendências atuais exigem que a ação humana se projete na esfera natural (SUERTEGARAY, 2005).

No início do século $X X$ os estudos integrados da paisagem pelo viés geossistêmico passaram a ganhar mais conhecimento. Carlos A. F. Monteiro foi um dos precursores da inserção dos geossistemas na escola brasileira com bases soviéticas (CAVALCANTI e CORRÊA, 2016).

A essência dos fatos geográficos vai variar com base em suas interações, combinações, hierarquias e organização socioeconômicas (SUERTEGARAY; 
MORETTI, 2014). Neste sentido, deve-se aplicar ao estudo espacial a devida atenção ao componente antrópico no contexto natural, como atuante na produção da paisagem (TROPPMAIR, 2000). Foi nesse contexto que Monteiro (2001) realizou seu trabalho no Baixo São Francisco, contextualizando sua área de estudo sem a ótica específica de determinada área geográfica.

Em sua obra, Monteiro (2001) desenvolveu um "esquema geral das relações entre o quadro natural e a ocupação humana" (MONTEIRO, 2001, p. 17). A partir deste esquema fica possível identificar como que a técnica (ocupação antrópica e respectivos modos de produção) trabalha na produção da paisagem. Uma abordagem geográfica dirigida ao planejamento deve incorporar integralmente os elementos sistêmicos para auxiliar na tomada de decisões (CHRISTOFOLETTI, 1999), incorpora-se, então, caráter político aos geossistemas:

Fica bem claro que o geossistema e sua análise é uma tentativa de melhoria na investigação da "Geografia Física" (Parte II - A Geografia Física à luz do estudo dos Geossistemas). Fica também muito claro que a modelização dos geossistemas à base de sua dinâmica espontânea e antropogênica e do regime natural a elas correspondente visa, acima de tudo, promover uma maior integração entre o natural e o humano (MONTEIRO, 2001, p. 47).

Na narrativa da eclosão da pesquisa geográfica a partir da ótica geossistêmica, emergia a possibilidade da Geografia se aprimorar como veículo de planejamento (NEVES, 2019). A compreensão dos fenômenos e as diversas maneiras com que eles se materializam no espaço convergem para um sistema complexo, hierarquizado e dinâmico (PEREZ FILHO et al., 2008). Desta maneira, os diagnósticos para potencialidades e fragilidades socioambientais da paisagem são estruturados pela episteme geográfica (BARREIROS, 2017).

A geografia brasileira tem trabalhado bastante na questão do paradigma geossistêmico (DIAS; PEREZ FILHO, 2018). É comum em eventos, revistas, ou trabalhos acadêmicos, o termo "geossistema" aparecer como uma proposta de se 
trabalhar a paisagem. O objetivo desses trabalhos, comumente, é a organização espacial, bem como solucionar problemas ambientais e sociais (SOUZA et al., 2020).

A problemática que surge neste cenário está associada a dicotomia que perturba a geografia desde o século XVIII (MORAES, 2003). Ao buscar uma relação direta entre os fatores naturais e sociais, o pesquisador pode cometer o equívoco de diminuir a complexidade que emerge desta relação, pois o discurso ambiental na área de geografia é generalista e não representa a realidade da paisagem (LIMA, 2015).

Ao se fazer uma busca pela explicação de determinado espaço, se organizar ou se hierarquizar de determinada maneira, a complexidade das diferentes culturas e grupos sociais deve ser incorporada na análise (LIMA, 2015). O exercício de colocar em pé de igualdade a natureza e a sociedade, pelo viés geossistêmico, implica em analisar a variável antrópica pela ótica hipotético-dedutiva, com rigor matemático (RODRIGUEZ; SILVA, 2019). É nesse momento que fica evidente o equívoco geográfico em análises geossistêmicas.

A complexidade das ciências humanas coloca em vigor que os fatos sociais não podem ser reduzidos às suas dimensões externas, observáveis e a mensurações (MOREIRA, 2008). A partir do momento em que se compreende que os fenômenos sociais são historicamente condicionados e culturalmente determinados, as leis matemáticas que explicam a natureza não explicam os fatos sociais (SOUZA, 2013).

É este ponto que o presente texto busca destacar, que estudos geográficos apoiados na Teoria dos Geossistemas tendem a utilizar certa área do conhecimento geográfico como alicerce, em geral, da geografia física. O geógrafo, desde sua formação, seleciona a área com que tem mais afinidade, e carrega essa subjetividade por toda sua formação (MOREIRA, 2008). Ao elaborar uma análise geossistêmica, a probabilidade dele se apoiar na sua área de afinidade é muito 
grande, seja ela a geomorfologia, a climatologia ou a pedologia. E ao se deparar com a variável antrópica, a falta de afinidade com a geografia humana tende a deixar questões referentes ao paradigma científico-social isoladas, do ponto de vista metodológico (SOUZA, 2013).

Essa situação pode até enfraquecer o paradigma holístico, mas isso não significa a exclusão do paradigma geossistêmico (SOUZA et al., 2020). Os sistemas socioculturais e econômicos não constituem categoria antagônica ao sistema natural, mas sim uma complexa engrenagem do grande mecanismo, a paisagem (VITTE, 2007). Na medida em que o meio técnico-científico-informacional se intensifica ao longo da história, a complexidade do estudo geográfico pelo paradigma geossistêmico também se intensificam (SOUZA, 2013).

No entanto, uma questão epistemológica emerge nesse cenário de evolução da teoria geossistêmica na escola brasileira: "como devemos atribuir os geossistemas tendo em vista a dualidade geográfica, tanto nas universidades quanto na aplicação prática da ciência?" Os questionamentos da relação entre a paisagem e a geografia são complexos pois dependem da relação da sociedade com os elementos naturais. Sobre essa questão, Barreiros (2017) elenca uma síntese sobre o paradigma sistêmico dentro da Geografia, onde este comporia uma vertente de estudos sobre a paisagem com viés naturalista e capaz de compreender que as transformações da superfície terrestre ocorrem por processos naturais e antrópicos.

Deve-se ressaltar que a conjugação de métodos de investigação deve se ajustar às necessidades e objetivos do estudo e do pesquisador (ALVES, 2010). Será sempre almejado o máximo de compreensão da dinâmica resultante da inter-relação sociedade-natureza que predomina no recorte de paisagem estudado (CUNHA; MENDES 2005). É nesse contexto que os presentes autores consideram que a análise geoambiental com bases sistêmicas oferece um caminho para a análise dos atributos e agentes que interagem no sistema 
ambiental.

Para uma proposta de organização espacial ser bem sucedida ela necessita da compreensão dos processos de ocupação e como este foi realizado, ou seja, como os fatos naturais interferem nas ações humanas, tomando-as como fator morfogênico na dinâmica socioambiental (ROSS; DELL PRETTE, 2011).

Ao destacar a importância dos zoneamentos ambientais na produção e organização do espaço, o paradigma geossistêmico oferece caminhos para a concretização deste objetivo (ALVES, 2010). O zoneamento parte do diagnóstico socioambiental para a elaboração de um prognóstico, assim, constrói-se a integração do conhecimento natural para o planejamento social.

\section{A TEORIA GEOSSISTÊMICA COMO PROPOSTA INTEGRADORA DO ESPAÇO}

Quando se fala na aplicabilidade da Teoria dos Geossistemas para o espaço brasileiro, deve-se levar em consideração a realidade socioeconômica e ambiental do país. No modo capitalista de produção, o lucro prevalece sobre a existência do ser humano, tanto quanto componente social, quanto natural (MOREIRA, 2008). A visão do geógrafo deve estar atenta para as complexidades que o espaço brasileiro apresenta (SOUZA, 2013).

É comum no cenário acadêmico a busca pela conservação da natureza, pelo uso racional dos recursos e pelo desenvolvimento sustentável nos trabalhos desenvolvidos (SOUZA, 2010). Os estudos geossistêmicos têm se preocupado com esses cenários:

Um estudo ambiental tem que partir de um diagnóstico de problemas e, se os problemas forem muitos e complexos, há necessidade de selecioná-los por prioridades. As prioridades podem obedecer a critérios vários, a começar pelo interesse da comunidade; interesse dos órgãos administrativos, interesse dos próprios pesquisadores, ou ainda atender à disponibilidade de recursos naturais, técnicos e humanos (PENTEADO-ORELLANA, 
1985, p. 135)

A literatura geográfica tem auxiliado na elaboração de zoneamentos ambientais, com a construção de diagnósticos e prognósticos (SANTOS, 2019). Para este propósito, a análise geossistêmica fornece enorme subsídio para a organização espacial. Um dos caminhos utilizados é a análise de Unidades de Paisagem de Crepani et al. (2001).

As unidades de paisagem natural (UPN) são classificadas como unidades territoriais, delimitadas por um recorte espacial, que combinam uma série de eventos e interações (SPORL; ROSS, 2004). A análise de uma UPN depende do conhecimento da gênese fisiográfica da área de estudo, além das formas de evolução dos processos e da ocupação humana (SPORL; ROSS, 2004). Para Crepani et al. (1996):

O conhecimento dos mecanismos que atuam nas unidades de paisagem natural permite orientar as atividades a serem desenvolvidas dentro do polígono de intervenção antrópica, de maneira a evitar agressões irreversíveis e obter maior produtividade, além de dirigir ações corretivas dentro daqueles polígonos onde o uso inadequado provoca conseqüências desastrosas (CREPANI et al., 2001, p. 16).

Além das UPN, os zoneamentos geoambientais surgem como instrumentos, baseados em análises geossistêmicas, para a coordenação e arrumação do espaço geográfico (SANTOS, 2019). Ao considerar os pressupostos de Tricart (1977), na conjuntura dos processos pedogenéticos e morfogenéticos se formulam os graus de instabilidade e estabilidade da paisagem (MONTEIRO, 2001). Estabelecida essa relação com bases geomorfológicas, os zoneamentos corroboram para a compreensão do perfil socioeconômico com bases físiconaturais.

As orientações que um zoneamento busca planejar se baseiam em 
aspectos abióticos, bióticos e antrópicos da paisagem, fundamentados no anseio popular (SANTOS, 2019). Desta maneira, o planejamento pode se dedicar às áreas de acordo com suas especificidades e necessidades. Compreender a dinâmica espacial sob a ótica do potencial ecológico e da exploração biológica, que convergem para o quadro de atividades humanas sobre o meio, permite identificar a forma com que a condicionante antrópica age na paisagem (NEVES et al., 2014).

Neste contexto, as variáveis físicas, como relevo, hidrografia, solos, rochas, fauna e flora, devem ser espacialmente identificadas, estabelecidos os padrões de espacialização, quantificados em termos morfogenéticos e pedogenéticos (NEVES et al., 2014). Assim, as potencialidades e fragilidades para o uso e ocupação da paisagem são definidas para que a biostasia da paisagem não entre em colapso.

Para que a organização espacial seja bem sucedida, deve ser limitada uma unidade espacial, como as bacias hidrográficas (CHRISTOFOLETTI, 1999). Nesta perspectiva sistêmica, SANTOS (2019) elaborou o zoneamento geoambiental da Área de Proteção Ambiental da bacia hidrográfica do rio Machado, no sul de Minas Gerais.

O trabalho se baseou no diagnóstico do meio físico e socioeconômico da área de estudo e objetivou fornecer uma proposta de zoneamento que atendesse as demandas sociais e respeitasse a dinâmica natural da bacia. Para isso, foram delimitadas cinco zonas geoambientais (Tabela 2) para orientação da organização espacial (SANTOS, 2019, p.154).

O trabalho desenvolvido por Santos (2019) é um claro exemplo de como a Teoria dos Geossistemas trouxe para a geografia a possibilidade de se inserir como instrumento de planejamento. A caracterização da paisagem, com bases geomorfológicas, para a ocupação do espaço e desenvolvimento da sociedade é fundamental para manter a biostasia da área. O zoneamento tem capacidade de fornecer dados e indicações para o planejamento, mas é necessário o 
aprofundamento das condições socioculturais e econômicas da bacia hidrográfica estudada.

Tabela 2: Zonas geoambientais utilizadas por Santos (2019)

\begin{tabular}{l|l}
\hline Zonas Geoambientais & \multicolumn{1}{c}{ Caracterização } \\
\hline $\begin{array}{l}\text { Zona Proteção Ambiental } \\
\text { (ZPA) }\end{array}$ & $\begin{array}{l}\text { Fragmentos remanescentes de Mata Atlântica, } \\
\text { frágeis do ponto de vista ambiental, que apresentam } \\
\text { intensa atividade antrópica, oferecendo perigo para } \\
\text { a manutenção e conservação das margens do rio } \\
\text { Machado. Desta maneira, é essencial o } \\
\text { estabelecimento de regras de proteção ambiental } \\
\text { para essas zonas. }\end{array}$ \\
\hline Zona de Interesse & $\begin{array}{l}\text { São caracterizadas por pequenas porções de mata } \\
\text { nativa e plantações de ciclo longo, como a } \\
\text { cafeicultura. Santos (2019) descreveu a morfologia } \\
\text { destas zonas com morros e colinas de declives } \\
\text { suaves, que favorecem a cafeicultura. Onde } \\
\text { prevalecem processos erosivos laminares, como } \\
\text { sulcos e ravinas. Desta maneira, o autor sugere que } \\
\text { nessas unidades devem ser priorizadas atividades } \\
\text { que protejam os remanescentes florestais e os solos }\end{array}$ \\
\hline $\begin{array}{l}\text { Zona de Interesse } \\
\text { Hidrológico (ZIH) }\end{array}$ & $\begin{array}{l}\text { Planícies de inundação e suas margens. São } \\
\text { caracterizadas como Áreas de Proteção Permanente } \\
\text { (APP) de acordo com o Código Florestal (2012). Logo, } \\
\text { devem ser protegidas integralmente para que não } \\
\text { se iniciem processos de desequilíbrios ambientais } \\
\text { na dinâmica fluvial do rio Machado. }\end{array}$ \\
\hline
\end{tabular}




\begin{tabular}{|c|c|}
\hline $\begin{array}{l}\text { Zona Restrição Produtiva } \\
\text { (ZRP) }\end{array}$ & $\begin{array}{l}\text { Caracterizadas por morros íngremes com solos } \\
\text { pouco desenvolvidos, onde ocorrem cultivos de } \\
\text { altitude, como o plantio do café, e áreas de mata } \\
\text { nativa. A ocupação dessas áreas de maneira } \\
\text { irregular pode desencadear uma gama de processos } \\
\text { erosivos prejudiciais à sociedade e ao meio } \\
\text { ambiente. }\end{array}$ \\
\hline $\begin{array}{l}\text { Zona de Adequação } \\
\text { Produtiva } 1 \text { (ZAP 1) }\end{array}$ & $\begin{array}{l}\text { São caracterizadas por colinas e morros com } \\
\text { encostas suaves, onde prevalecem agriculturas de } \\
\text { ciclo curto. Santos (2019) descreveu essas zonas } \\
\text { como as que mais concentram escoamentos } \\
\text { lineares, que prejudicam os corpos hídricos e a } \\
\text { fertilidade do solo. Recomendou que essa unidade } \\
\text { seja acompanhada de técnicas de conservação dos } \\
\text { solos para evitar a instabilidade do sistema. }\end{array}$ \\
\hline $\begin{array}{l}\text { Zona de Adequação } \\
\text { Produtiva } 2 \text { (ZAP 2) }\end{array}$ & $\begin{array}{l}\text { Caracterizadas por encostas suaves de colinas com } \\
\text { culturas temporárias de soja e milho. Os efeitos da } \\
\text { falta de manejo do solo nessa área afetam o } \\
\text { reservatório da Usina Hidrelétrica de Furnas, e } \\
\text { intensificam os processos de assoreamento dos } \\
\text { corpos hídricos. Recomendam-se, então, técnicas de } \\
\text { proteção dos solos. }\end{array}$ \\
\hline
\end{tabular}

Essa situação ressalta o problema discutido no início do presente trabalho, da falta de articulação da unidade geográfica. Essa dualidade não necessariamente enfraquece a Geografia, ela apresenta um cenário onde algumas necessidades surgem, como por exemplo, a compreensão da complexidade da paisagem. Qualquer planejamento que busque ser efetivado deve considerar as condições sociais da área de estudo. A estruturação social é historicamente e 
culturalmente condicionada (SOUZA, 2013), logo, não se deve generalizar a aplicação de estudos ambientais.

\section{CONSIDERAÇÕES FINAIS}

A Teoria dos Geossistemas é considerada uma proposta sólida da geografia física para os estudos da paisagem sob a ótica sistêmica. A premissa holística de uma análise teórico-metodológica influenciada por esta perspectiva busca desafiar os limites e extrapolar o conformismo de que a análise integradora peca ao partir de uma área específica do conhecimento geográfico, comumente, a geomorfologia.

A complexidade da paisagem resulta em metodologias e modelos complexos para sua explicação e organização. A sistematização e consolidação de perspectivas que se dedicam ao propósito do planejamento devem se preocupar em não diminuir a complexidade da relação sociedade-natureza.

Neste sentido, é preciso cuidado ao delimitar a escala de análise da abordagem geossistêmica. Cada recorte ou unidade espacial definidos são fundamentais para o processo de compreensão das interações espaciais. Assumese que a dicotomia da unidade geográfica deve ser admitida e trabalhada no plano teórico-metodológico das diferentes escalas do espaço-tempo. Assim, não se reduz a influência das diferentes culturas e das relações sociais que se materializam no espaço e modificam a paisagem.

O presente trabalho buscou destacar as principais questões que cercam a teoria geossistêmica. Os autores explicitaram que devem ser consideradas as variáveis abióticas, bióticas e culturais da paisagem. Mas isso não significa admitir que exista uma única forma de se avaliar a sociedade na perspectiva sistêmica.

Uma das vantagens da teoria geossistêmica é a possibilidade de investigação dos diversos aspectos da paisagem, como estrutura, evolução e dinâmica. A premissa de que o surgimento desta teoria está associado à geografia 
física não deve ser motivo para a diminuição da complexidade paisagística na análise geográfica. É preciso que aqueles que estejam inseridos no contexto geográfico de produção científica estejam engajados nos temas da geografia que contribuem para a teoria, como a cartografia e ecologia de paisagens.

Não se considera que outras áreas do conhecimento geográfico, como a hidrologia e a climatologia, por exemplo, serão abordadas resumidamente e sem aprofundamento epistemológico. A essência geográfica deve ser priorizada para que se alcance o objetivo da organização espacial, e a Teoria dos Geossistemas tem nos mostrado um caminho para essa finalidade.

A escala de análise é fundamental para delimitar a lente que guiará a análise da variável antrópica. As bacias hidrográficas, como já destacou Christofoletti (1999), aparecem como recortes escalares capazes de nortear uma pesquisa geossistêmica. A pesquisa carece de um ponto de partida e na maioria dos trabalhos realizados sob a perspectiva geossistêmica, esse ponto costuma ser a geomorfologia. Essa área do conhecimento geográfico permite compreender as relações que subsidiam o comportamento social no espaço (MONTEIRO, 2001). O presente texto admite que as integrações, em diferentes níveis escalares, da paisagem, podem ser compreendidas pela geomorfologia dentro da perspectiva geossistêmica.

Não se exclui a necessidade de novos aprimoramentos nas perspectivas integradoras da paisagem. A relação da sociedade com a natureza é complexa, logo, os diagnósticos e prognósticos devem salientar maneiras coerentes ao desenvolvimento socioambiental. Neste processo, os geógrafos têm papel fundamental na compreensão da dinâmica socioespacial, através da elaboração de planos de ordenamento territorial e gestão do espaço.

\section{REFERÊNCIAS BIBLIOGRÁFICAS}

ALVES, Neise Mare de Souza. Análise geoambiental e socioeconômica dos 
municípios costeiros do litoral norte do estado de sergipe - diagnóstico como subsídio ao ordenamento e gestão do território. 2010. 348 f. Tese (Doutorado) Curso de Geografia, Universidade Federal de Sergipe, São Cristóvão, 2010.

AMORIM FILHO, Oswaldo Bueno. A Formação do Conceito de Paisagem Geográfica: os Fundamentos Clássicos, in: Paisagens, vol. 3. Coord. Oliveira, L.; Machado, L. M. C. P. Rio Claro: UNESP, 1998.

BARREIROS, A. M. Da paisagem como objeto da Geografia: repasse teórico e sugestão metodológica. 2017, 116f. Tese de Doutorado, Universidade de São Paulo, Faculdade de Filosofia, Letras e Ciências Humanas, São Paulo, 2017.

BERTALANFFY, L. von. The Theory of Open Systems in Physics and Biology. Science, v. 111 , january 13 , pp. $23-29,1950$ a.

BERTRAND, G. Paisagem e Geografia Física global: esboço metodológico. Caderno de Ciências da Terra. São Paulo, n.13, p. 1-27, 1972.

BERTRAND, G. Paisagem e Geografia Física Global: esboço metodológico. Traduzido do francês por Olga Cruz. Caderno de Ciências da Terra, IGEOG/USP, n 13, 1972. $27 \mathrm{p}$.

BERTRAND, G. Paysage et géographie physique globale: esquisse méthodologique. Revue géographique des Pyrénées et du Sud-Ouest, t. 39, f. 3, pp. $249-272,1968$.

BERTRAND, G.; BERTRAND, C. Uma geografia transversal e de travessias: o meio ambiente através dos territórios e das temporalidades. Maringá: Massoni, 2007. $332 p$.

CARVALHO, Rodrigo Guimarães de; MEIRELES, Antonio Jeovah de Andrade. Dinâmica ambiental como critério para o zoneamento do litoral leste de Fortaleza - CE. Mercator - Revista de Geografia da UFC, vol. 7, núm. 14, pp. 167-178, 2008. Disponível em: Redalyc.DINÂMICA AMBIENTAL COMO CRITÉRIO PARA O 
ZONEAMENTO DO LITORAL LESTE DE FORTALEZA - CE. Acesso em: 25 nov. 2021.

CAVALCANTI, L. C. S.; CORRÊA, A. C. B. Geossistemas e Geografia no Brasil. Revista Brasileira de Geografia, v. 61, n², pp. 3 - 33, 2016.

CAVALCANTI, Lucas Costa de Souza; CORREA, Antonio Carlos de Barros. Problemas de hierarquização espacial e funcional na ecologia da paisagem: uma avaliação a partir da abordagem geossistêmica. Geosul, Florianópolis, v. 55, n. 28, p. 143-162, jun. 2013.2 Disponível em: https://periodicos.ufsc.br/index.php/geosul/article/view/2177-

5230.2013v28n55p143. Acesso em: 25 nov. 2021.

CHRISTOFOLETTI, A. Modelagem de sistemas ambientais. São Paulo: Edgard Blücher, 1999.

CREPANI, E.; MEDEIROS, J. S.; AZAVEDO, L. G.; DUARTE, V.; HERNANDEZ, P.; FLORENZANO, T.; BARBOSA, C. Sensoriamento remoto e geoprocessamento aplicados ao zoneamento ecológico-econômico e ao ordenamento territorial. São José dos Campos-SP: INPE, 2001.

CUNHA, C. M. L.; CUNHA, S. B.; FREITAS, M. W. D. Geossistemas e Gestão Ambiental na bacia hidrográfica do rio São João - RJ. GEOgraphia. UFF. v. 6, n. 12, p. 87-110, 2004.

DIAS, R. L.; PEREZ FILHO, A. Novas considerações sobre geossistemas e organizações espaciais em Geografia. Sociedade e Natureza, v. 29, n. 3, p. 409-421, 12 abr. 2018.

DIAS, Renê Lepiani; OLIVEIRA, Regina Célia de. Análise das paisagens do litoral sul do estado de são paulo. Sociedade \& Natureza, Uberlandia, v. 24, n. 3, p. 505-517, set. $2012 . \quad$ Disponível em: https://www.scielo.br/j/sn/a/dkPYbNMqpX33ZTkW5TPH7fS/?format=pdf\&lang=pt . Acesso em: 25 nov. 2021. 
DUTRA-GOMES, R., VITTE, A. C. A Geografia Física e o objeto complexo: algumas flexibilizações do processual. Geosul, v. 26, n.50, p.08-38, 2009.

DUTRA-GOMES, R.; VITTE, A. C. Geossistema e Complexidade: sobre hierarquias e diálogo entre os conhecimentos. Ra'e Ga: Espaço Geográfico em Análise, v. 42, p. 149-164, 2017.

DUTRA-GOMES, R.; VITTE, A. C. O. Geossistema pela Complexidade: Uma releitura das Esferas Geográficas. Revista do Departamento de Geografia (USP), v. 35, p. 15 $27,2018$.

GUERRA, A. J. T.; MARÇAL, M. S. Geomorfologia ambiental. Rio de Janeiro: Bertrand Brasil, 2006.

LIMA, E. L. de. O mito do "fator antrópico" no discurso ambiental geográfico. Mercator, Fortaleza, v.14, n.3, p.109-122, 2015. Disponível em: https://doi.org/10.4215/RM2015.1403.0007 Acesso em: 08 jan. 2020.

MARQUES NETO, R. O zonal e o azonal na interpretação e classificação dos geossistemas do município de Lima Duarte, zona da mata mineira. GEOgraphia, v. 21, n. 45, p. 86 - 97, 7 jun. 2019.

MENDES, I. A. Proposta de análise integrada dos elementos físicos da paisagem: uma abordagem geomorfológica. Estudos geográficos, v. 3, n. 1, p. 111-120, 2005. MENDONÇA, F. A. Geografia Socioambiental. In: MENDONÇA, F.; KOZEL, S. (Org). Elementos de epistemologia da geografia contemporânea. Curitiba: UFPR, 2002. p. 121-143.

MONTEIRO, C. A. F. Geossistemas: a história de uma procura. São Paulo: Contexto, 2001.

MORAES, Antonio C. R. Geografia: pequena história crítica. 19ª Ed. SP: AnnaBlume, 2003. 
MOREIRA, R. Pensar e ser em Geografia: ensaios de história, epistemologia e ontologia do espaço geográfico. São Paulo: Contexto, 2008.

NEVES, Carlos Eduardo das; MACHADO, Gilnei; HIRATA, Carlos Alberto; STIPP, Nilza Aparecida Freres. A importância dos geossistemas na pesquisa geográfica: uma análise a partir da correlação com o ecossistema. Soc. nat., Uberlândia, v. 26, n. 2, p. 271-285, ago. 2014.

NEVES, Carlos Eduardo das. O uso do geossistema no brasil: legados estrangeiros, panorama analítico e contribuições para uma perspectiva complexa. 2019. $400 \mathrm{f}$. Tese (Doutorado) - Curso de Geografia, Geografia, Unesp, Presidente Prudente, 2019. Disponível em: https://repositorio.unesp.br/handle/11449/191431. Acesso em: 09 set. 2020.

NUNES, J. O. R. Práxis geográfica e suas conjunções. 2014. 150 f. Tese (Livre Docência em Geografia) Faculdade de Ciência e Tecnologia, Universidade Estadual Paulista, Presidente Prudente, 2014.

NUNES, L. S. A implementação da política de educação ambiental do município de Florianópolis: novas demandas ao Serviço Social. 2012. 228f. Dissertação (Mestrado em Serviço Social) - Programa de Pós-Graduação em Serviço Social, Universidade Federal de Santa Catarina, Florianópolis, 2012.

OLIVEIRA, Glaucia Silva. O SISTEMA GTP (GEOSSISTEMA - TERRITÓRIO - PAISAGEM) NO MUNICÍPIO DE ARCOS - MG: Uma análise da paisagem. 2019. 152 f. Dissertação (Mestrado) - Curso de Geografia, Geografia, Universidade Federal de Minas Gerais, Belo Horizonte, 2019.

PENTEADO, O. M. M. Metodologia Integrada no estudo do meio ambiente. Geografia, Instituto de Geociências, UFMG, Belo Horizonte,10, v.20, p.125-148, 1985.

PEREZ FILHO, A.; QUARESMA, C. C.; RODRIGUES, T. R. I. Ação antrópica como 
agente transformador da organização espacial em bacias hidrográficas. Diez años de cambios en el Mundo, en la Geografía y en las Ciencias Sociales, 1999-2008. Actas del X Coloquio Internacional de Geocrítica, Universidad de Barcelona, 2008. RODRIGUES, C. A teoria geossistêmica e sua contribuição aos estudos geográficos e ambientais. Revista do Departamento de Geografia. São Paulo. v. 1, n. 14, p. 112$122,2001$.

RODRIGUEZ, J. M. M.; SILVA, E. V. A. A Classificação das Paisagens a partir de uma Visão Geossistêmica. Mercator. Fortaleza. v 1, n. 1, p. 95-112, 2002.

RODRIGUEZ, J. M. M.; SILVA, E. V. Teoria dos Geossistemas: o legado de V. B. Sochava: volume I. Fundamentos Teórico-Metodológicos. Fortaleza: Edições UFC, 2019.

RODRÍGUEZ, J. M. M.; SILVA, E. V.; VICENS, R. S. O legado de Sochava. GEOgraphia, ano 17, n³3, 2015.

ROSS, J. L. S.; DEL PRETTE, M. E. Recursos Hídricos e as Bacias Hidrográficas: Âncoras do Planejamento e Gestão Ambiental. Revista do Departamento de Geografia. vol. 12, p. 89-121. São Paulo-SP, 2011.

ROSS, J. L. S.; DEL PRETTE, M. E. Recursos hídricos e as bacias hidrográficas: âncoras do planejamento e gestão ambiental. Revista do Departamento de Geografia, [S. I.], v. 12, p. 89-121, 2011. DOI: 10.7154/RDG.1998.0012.0005. Disponível em: https://www.revistas.usp.br/rdg/article/view/53736. Acesso em: 25 nov. 2021.

ROSS, J. L. S. Ecogeografia do Brasil: Subsídio para o planejamento ambiental. Rio de Janeiro, Oficina de Texto, 2006, 208p.

SANTOS, Clibson Alves dos. Diagnóstico e zoneamento geoambiental da APA da Bacia Hidrográfica do Rio Machado-MG. Caderno de Geografia, Campinas, v. 29, n. 1, p.144-163, ago. 2019. 
SEMENOV, Y. M.; SNYTKO, V. A. The 50th Anniversary of the Appearance of V. B. Sochava's First Article on the Geosystem. Geography and Natural Resources. Vol. 34, No. 3, 2013. p. 5-8.

SOCHAVA, V. B. Modern Geography and its tasks in Siberia and the Soviet Far East. Soviet Geography, v. 9, issue 2, pp. 80 - 95, 1968 a.

SOCHAVA, V. B. The development of geographic science in Siberia an the Soviet Far East over the last 50 years (1917-67). Soviet Geography, v. 9, issue 4, pp. 293 304,1968 b.

SOUZA, J. C. O. de. Identificação de geossistemas e sua aplicação no estudo ambiental da bacia hidrográfica do rio São Miguel - Alagoas. 2013. Dissertação (Mestrado em Geografia Física) - Universidade Federal de Pernambuco, Recife, 2013.

SOUZA, Lucas Barbosa de; LIMA, Péricles Souza; SANTOS, Simoni Rodrigues. Da teoria dos geossistemas à geografia física crítica: o que há de novo na busca por abordagens integradoras na ciência geográfica? Revista Okara: Geografia em Debate, João Pessoa, v. 14, n. 1, p. 122-136, jul. 2020. Disponível em: https://periodicos.ufpb.br/ojs2/index.php/okara. Acesso em: 09 ago. 2020.

SOUZA, M. A. A. DE. Meio ambiente e desenvolvimento sustentável. As metáforas do capitalismo. Revista Cronos, v. 10, n. 2, 17 jan. 2013.

SOUZA, R. J. de. O sistema GTP (Geossistema-Território-Paisagem) aplicado ao estudo sobre as dinâmicas socioambientais em Mirante do Paranapanema-SP. 2010. Dissertação (Mestrado em Geografia) - Universidade Estadual Paulista, Presidente Prudente, 2010.

SPORL, Christiane; ROSS, Jurandyr L. S. Análise comparativa da fragilidade ambiental com aplicação de três modelos. GEOUSP - Espaço e Tempo, São Paulo, v. 15, n. 1, p. 39-49, abr. 2004. 
SUERTEGARAY, D. M. A. O atual e as tendências do ensino e da pesquisa em Geografia no Brasil. Revista do Departamento de Geografia (USP), São Paulo, v. 16, p. 38-45, 2005.

SUERTEGARAY, D. M. A.; MORETTI, E. C. Considerações sobre o eixo temático Natureza no contexto dos Encontros Nacionais de Geógrafos (Brasil) 2008-2012. Terra Livre, ano 30, v. 2, n. 42, 2014.

TRICART, J. Ecodinâmica. Rio de Janeiro: IBGE/SUPREN, 1977.

TROPPMAIR, H. Geografia Física e a Dinâmica das Paisagens Brasileiras. Anais do XII Simpósio de Geografia Física Aplicada. Natal (RN), 2007. (Entregue para publicação).

TROPPMAIR, H. Geossistemas e geossistemas paulistas. Rio Claro: UNESP, 2000. TROPPMAIR, Helmut; GALINA, Marcia Helena. Geossistemas (Geosystems). Mercator, Fortaleza, v. 5, n. 10, p. p. 79 a 90, nov. 2006. Disponível em: Redalyc.GEOSSISTEMAS. Acesso em 21 nov. 2021.

VITTE, A. C. O desenvolvimento do conceito de paisagem e a sua inserção na Geografia Física. Mercator, Fortaleza, v.6, n.11, p.71-78, 2007.

WULF, A. A invenção da natureza: a vida e as descobertas de Alexandre von Humboldt. São Paulo: Planeta, 2016. 